\title{
NON-STATIONARY MODEL OF THE SOLAR CORE
}

\author{
S.F. Skoromnaya ${ }^{1}$, V.I. Tkachenko ${ }^{1,2}$ \\ ${ }^{1}$ National Science Center “Kharkov Institute of Physics and Technology”, Kharkiv, Ukraine; \\ ${ }^{2}$ V.N. Karazin Kharkiv National University, Kharkiv, Ukraine \\ E-mail: tkachenko@kipt.kharkov.ua
}

The main parameters of the standard model of the Sun are considered, according to which the Sun is considered as a spherically symmetric and quasistatic star, and thermonuclear reactions of the pp-cycle mainly occur inside it and the energy is uniformly released at a rate of $2 \cdot 10^{-4} \mathrm{~J} /(\mathrm{kg} \cdot \mathrm{s})$. Based on observational data it was concluded that the Sun is not a star with uniformly ongoing processes, it is characterized by oscillatory processes and flashes. It is proposed to consider the non-stationary model of the Sun, in which it is required to take into account the existence of electromagnetic waves in the plasma of the solar core and, as a result, the existence of wave collapses (WC). A three-dimensional axially symmetric WC is considered and an estimate of the velocity of removal of the plasma of the solar core during the development of a three-dimensional axially symmetric WC is given. For the considered WC the existence of three directions of flows of elementary plasma volumes relative to the observer is demonstrated: one direction is due to the moving the elementary plasma volume from the observer and the other - to him. The third direction of moving of the elementary plasma volumes is perpendicular to the direction of observation and their velocity relative to the observer is zero. It is concluded that the existence of such motions of elementary plasma volumes during the development of WC can leave a definite imprint on the parameters of the synthesis products in them.

PACS: 52.35.-g, 52.35.Fp, 11.80.-m; 13.15.+g

\section{STANDARD SOLAR MODEL}

The Standard Solar Model (SSM) is the representation of the Sun in the form of a gas sphere with various degrees of hydrogen ionization depending on the radius. Hydrogen is in a fully ionized state, i.e. is a fully ionized gas in the inner region of the Sun. This model describes a spherically symmetric and quasistatic star, the internal structure of which is described by several differential equations of hydrostatic equilibrium obtained from the basic laws of physics. SSM is used to test the theory of star evolution $[1,2]$.

SSM assumes that the Sun consists of 3 zones [2]:

1. The inner zone has a size of $R<R_{1}=7 \cdot 10^{6} \mathrm{~m}$, which is a small part of the star, but just in this zone thermonuclear reactions of the pp-cycle mainly proceed and energy is released: $E=2 \cdot 10^{-4} \mathrm{~J} /(\mathrm{kg} \cdot \mathrm{s})$. Its temperature $T \sim 1.5 \cdot 10^{7} \mathrm{~K}$, pressure and matter density $P \sim 10^{8} \mathrm{MPa}$ and $\rho \sim(1.5 \ldots 1.6) \cdot 10^{5} \mathrm{~kg} / \mathrm{m}^{3}$. Energy from this zone as a result of weak convection is transferred to zone 2 .

2. The static radiation zone is located in the interval of $R_{1}<R<R_{2}=4.9 \cdot 10^{8} \mathrm{~m}$. In this zone due to X-ray radiation the temperature rapidly decreases from $10^{7} \mathrm{~K}$ to $10^{6} \mathrm{~K}$. The mean free-path length of X-ray radiation $l \sim 1 / \rho \sigma$ is small and diffusion from the center to the surface takes $10^{6} \ldots 10^{7}$ years, i.e. radiation is transmitted very slowly to zone 3 .

3 . The external convective zone is in the interval $R_{2}<R=7 \cdot 10^{8} \mathrm{~m}$ and contains about $\sim 2 \%$ of the total mass of the Sun. The temperature in this zone varies from $10^{6}<T<6 \cdot 10^{3} \mathrm{~K}$ and the density is of the order of $\rho \sim 1.5 \cdot 10^{3} \mathrm{~kg} / \mathrm{m}^{3}$. The outside part of this zone is the photosphere. Above this zone is the chromosphere with $\rho_{x p} \sim 3 \cdot 10^{-9} \mathrm{~kg} / \mathrm{m}^{3}$ and then comes the corona with a density of $\rho_{\kappa}=10^{-12} \mathrm{~kg} / \mathrm{m}^{3}$.

SSM well describes the experimental results based on data obtained from sensing the Sun. The strongest evidence of its validity would be direct observation of solar neutrinos. However, the disagreement in the results arising from the SSM of the estimated number of neutrinos and experimental data led to the discovery of the phenomenon of neutrino oscillations confirmed in a number of experiments [3].

The above data are based on the Sun quasistaticity. It means that the thermonuclear reactions of synthesis of pp-cycle, $4 p \rightarrow^{4} \mathrm{He}+2 e^{+}+2 v_{e}$ [4] as basic on the Sun [2], uniformly release energy in the inner zone of the Sun at a rate of $2 \cdot 10^{-4} \mathrm{~J} / \mathrm{kg}$ per second. As a result of the reaction four protons are combined into a helium nucleus with the emission of two positrons and two electron neutrinos. Thus, hydrogen is "converted" into helium in the Sun.

In fact, the uniformity of energy release is doubtful, since quasistaticity in the inner zone of the Sun is disturbed by the waves propagating in the plasma. The existence of waves inside the Sun, for example, is indicated by the fact of occurrence of the Sun radius fluctuations [5]. Besides, a faster rotation of the solar core relative to the outer layers has recently been observed. This rotation generates g-modes inside the Sun which are the oscillations caused by gravity [6].

The availability of the above-mentioned oscillations can excite electromagnetic waves in the plasma, which in turn will initiate electromagnetic wave collapses (WC) [7 - 14] and, as a result, the appearance of accelerated flows of solar matter in the solar core. The accelerated flows of solar matter can occur as a result of explosive removal of particles from the cavity formed in the plasma due to the effect of ponderomotive forces and represent a density hole.

Recognition with fact of existence of accelerated flows of solar matter in the solar core caused by wave collapses can change the conclusions based on SSM and give a new approach to the study of solar neutrinos.

In this paper we consider the conditions for originating the wave collapses in the inner zone of the Sun. 


\section{WAVE COLLAPCE}

Wave collapse (WC) - explosive in time increase of energy density in a given volume. WC is one of the fundamental processes in the theory of wave propagation in dispersive media. In some cases WC is a result of solving the nonlinear Schrödinger equation (NSE).

This equation for a complex field $\psi$ has the form:

$$
i \psi_{t}+\Delta \psi+|\psi|^{2} \psi=0
$$

where index $t$ denotes a temporal partial derivative; $\Delta$ - Laplacian.

NSE is an analogue of the dispersion nonlinear equation in partial derivatives and one of the fundamental equations of nonlinear physics, which has attracted the attention of researchers for more than half a century [15-17].

There are many examples of WC implementation. These include the collapse of Langmuir waves [6,7], self-focusing of the electromagnetic field in optical fibers $[9,10]$ and weakly nonlinear hydrodynamic disturbances on a static cosmic background [11], the behavior of deepwater waves and killer waves in an ocean [12, 13].

However, the above examples do not provide a complete list of WC implementations. The only thing that unites these processes is that they are all described by the nonlinear Schrödinger equation.

These studies have shown that in the two- and threedimensional NSE models the wave collapse, as a phenomenon of the formation of a singularity over a finite period of time, play the same fundamental role as the solitons that are realized in the one-dimensional model and are the wave formations of an equilibrium shape conserving in space.

In the case of multidimensional WC (multidimensional NSE model) the equilibrium is disturbed, the medium becomes unsteady and nonlinear processes determine WC dynamics. Study of the conditions of occurrence of the temporal dynamics of "explosive" increasing the amplitude of WC field is important because knowledge of WC main features makes it possible to evaluate the efficiency of a collapse as a non-linear mechanism of transformation of wave energy into other types of energy.

It should be noted that many studies have been devoted to WC development in various environments.

For example, strict NSE solutions, explosive solutions and their asymptotic behavior near critical sizes are discussed in detail in the review [17].

In $[18,19]$ the conditions of WC occurrence are discussed in detail and criteria for selecting the type of selfsimilar solutions for the numerical study of the NSE are given. As a rule, numerical calculations use various multidimensional difference algorithms. In some cases they violate conservatism and conservation laws; in others they take much time for calculation and require a large RAM.

A method for selecting NSE self-similar variables to describe the development of multidimensional WC was proposed first in [14]. It is demonstrated that the required self-similar variables along with the law of conservation of the number of quanta and the Hamiltonian ensure the conservation of the mean square radius of the wave train. As a result of selection of such self-similar variables transition to a non-inertial reference frame is realized, where $\mathrm{WC}$ do not occur and the dynamics of the wave train is determined by the equation for the axial coordinate.

The proposed self-similar variables in the two- and three-dimensional cases (axially symmetric and spherically symmetric WC) allow us to write the mean square of the radius of the wave train in a universal form: for both the two-dimensional and three-dimensional (spherically symmetric) cases, where the mean square of the radius of the wave train is constant and is equally expressed through the Hamiltonian of the system. It is shown that in physical variables (radius, time) the rate of development of a spherically symmetric WC is higher than two-dimensional.

An explosive increase of the field amplitude for an axially symmetric three-dimensional $\mathrm{WC}$ occurs along the axis of the system. In this case, there are two possible ways of WC developing.

The first way is observed when the characteristic size of the wave train along the axis $z$ exceeds the radial (a sphere stretched along the axis $z$ ). Then the dynamics of the development of the axial WC will continue until the axial half-width of the wave train coincides with its radius. In this case the $\mathrm{WC}$ transfers into the stage of a spherically symmetric WC and the rate of collapse development increases from $\left(t_{0}^{2}-t^{2}\right)^{-1 / 2}$ to $\left(t_{0}^{2}-t^{2}\right)^{-3 / 4}$.

The second way can be developed if the characteristic size of the wave train along the axis $z$ is less than the radial (a sphere compressed along the axis $z$ ). In this case the wave train with initially shape of a compressed sphere will be transformed into a "presolar disk" [14].

We consider the conditions of occurrence and give estimates of the characteristic parameters of the threedimensional axially symmetric WC in the plasma of the Sun inner zone.

\section{THREE-DIMENTIONAL AXIALLY SYMMETRIC WC}

First of all, during WC development we will be interested in the parameters characterizing the processes of plasma removal from the forming cavity. For an outside observer the elements of the plasma volume pushed out by the ponderomotive forces from the cavity will be in different reference frames. The first two reference frames are such that one moves from the observer, the other - towards. The third reference frame is such that the direction of motion of plasma volume elements is transverse to the observer's gaze direction in it.

For such reference frames the consideration of a three-dimensional axially symmetric WC is most preferable, since it is occurs more frequently in space [14] and, moreover, has different characteristic length scales in the radial and axial directions.

It is known from [14] that Jacobi functions $c n(z, k)$, defined as zeros, of the boundary of the wave train along the axis $z-z_{1,2}(0)= \pm h_{1}$, will move towards the origin of coordinates according to the law $z_{1,2}(t)= \pm h_{1} \cdot \sqrt{\left(t_{0}^{2}-t^{2}\right) t_{0}^{-2}}$, i.e. axial WC will develop, where $t$ is the time of the collapse development, $t_{0}$ is the time of its formation. Moreover, by virtue of choice of 
self-similar substitution [14] the radial size of the WC remains unchanged. Thus, the electric field will increase in time at the origin of coordinates. As consequence, non-uniformity of the field along the coordinate $z$ will lead to pushing out of the plasma by ponderomotive forces and formation of a cavity.

To determine the order of magnitude of the velocity of the elementary plasma volume movement we estimate the characteristic plasma parameters of the inner zone of the Sun.

They are as follows [1, 2]: plasma density $n_{e}=n_{i}=10^{32} \mathrm{~m}^{-3}$, temperature $T_{e}=1.3 \cdot 10^{3} \mathrm{eV}$, electron thermal velocity $V_{T i}=3.5 \cdot 10^{5} \mathrm{~m} / \mathrm{s}$, ion thermal velocity $V_{T e}=1.5 \cdot 10^{7} \mathrm{~m} / \mathrm{s}$, ionic Langmuir frequency $\omega_{p i}=2.1 \cdot 10^{15} \mathrm{~s}^{-1}$, ion sound velocity $C_{S}=4.6 \cdot 10^{5} \mathrm{~m} / \mathrm{s}$, wavelength of the ion sound $\lambda=1.4 \cdot 10^{-9} \mathrm{~m}$, Debye radius $\lambda_{D}=2.67 \cdot 10^{-11} \mathrm{~m}$.

Since the axial pushing out of the elementary plasma volume is faster than the radial one [14] let us estimate its moving velocity in this direction from the velocity of the wave train boundary moving. At that, account must be taken of the fact that the velocity of plasma removal $\tilde{V}_{1,2}$ from the cavity is directed in the opposite direction to the velocity of the wave train boundary movement, i.e. $\tilde{V}_{1,2}=-d z_{1,2} / d t$. Hence, we have:

$$
\tilde{V}_{1,2}=\mp \frac{h_{1}}{t_{0}} t\left(t_{0}^{2}-t^{2}\right)^{-\frac{1}{2}} \text {. }
$$

If we assume in (2) that $h_{1} \approx \lambda, t_{0} \approx \omega_{p i}^{-1}$, then at $t \rightarrow t_{0}$ the plasma moving velocity will increase explosively and can reach large, but not limiting light values $\left|\tilde{V}_{1}\right|=2.9 \cdot 10^{6} \frac{t}{t_{0}}\left(1-\left(\frac{t}{t_{0}}\right)^{2}\right)^{-\frac{1}{2}} \mathrm{~m} / \mathrm{s}, \quad\left(\left|\tilde{V}_{1}\right|<c=3 \cdot 10^{8} \mathrm{~m} / \mathrm{s}\right)$, since when the velocity of the elementary plasma volume is close to the light, the conditions of applicability of our consideration are violated.

The collapse stage will complete when the amplitude of plasma oscillations reaches such a value that the electron motion paths begin to intersect [8]. At that, the electron velocity will become higher than the thermal one; they will leave the cavity and take away the energy of Langmuir oscillations. After this, the cavity will "be collapsed" by the shock wave at the velocity of sound, the plasma will return to its original state and will again be ready to form a wave collapse.

As you can see, there are flows of elementary plasma volumes moving from the cavity in the solar core, characterized by a sufficiently high velocity $\left|\tilde{V}_{1}\right|$, and the flows of elementary plasma volumes moving in the opposite direction at a sound speed, caused by the "collapse" of the cavity.

Let us evaluate the consequences of WC development by the example of antineutrinos that are generated in the plasma core of the Sun in reference frames moving with velocity $\left|\tilde{V}_{1}\right|$ in the direction of the axis $x$ from the observer on the Earth and in the opposite direction. Let us represent neutrinos as wave functions with energies $\omega_{ \pm}$:

$$
v_{1,2}=\sin \left(k x-\omega_{\mp} t\right),
$$

where $\omega_{ \pm}=\omega \pm k \tilde{V}_{1}, \quad \omega<<\omega_{p i}, \quad k$ - frequency and wave number of the ion-sound wave. The superposition of waves (3) at a neutrino velocity of the order $c$ gives the path difference

$$
L=2 \pi \frac{C_{S} c}{\omega \tilde{V}_{1}} ; \quad k \tilde{V}_{1} t=k C_{S} \frac{\tilde{V}_{1}}{C_{S}} \frac{x}{c}=\omega \frac{\tilde{V}_{1}}{C_{S} c} x .
$$

If, for example, consider $\omega \approx 10^{8} \mathrm{~s}^{-1},\left|\tilde{V}_{1}\right| \approx 100 \mathrm{~m} / \mathrm{s}$, then the path difference will be of the order of $86.7 \cdot 10^{3} \mathrm{~m}$. This value corresponds in order of magnitude to the vacuum oscillation length $110 \cdot 10^{3} \mathrm{~m} \mathrm{[4]} \mathrm{in}$ the solar core.

Thus, the development of a three-dimensional axially symmetric WC is possible in the inner zone of the Sun. Under such conditions the plasma is removed from the forming WC cavity. At that, for the selected direction of observation the motion of elementary plasma volumes will be oriented in such a way that one volume moves from the observer and the other toward him. The velocity of the elementary plasma volume moving is zero for the direction of motion transverse to the direction of observation. The existence of such motions of elementary plasma volumes can leave a definite imprint on the parameters of the products of thermonuclear fusion in them.

\section{CONCLUSIONS}

A non-stationary model of the solar core is discussed in this paper. The main parameters of the standard model of the Sun, according to which the Sun is considered as a spherically symmetric and quasistatic star, are analyzed. The thermonuclear reactions of the pp-cycle proceed inside the Sun and the energy is uniformly released at a rate of $E=2 \cdot 10^{-4} \mathrm{~J} /(\mathrm{kg} \cdot \mathrm{s})$. Based on observational data it was concluded that the Sun is not a star with uniformly proceeding processes. It is characterized by oscillational perturbations of the internal volume and flares on the surface. Based on this, it was proposed to consider the nonstationary model of the Sun in which it is required to take into account the existence of electromagnetic waves in the plasma of the solar core and, as a result, the existence of WC. A three-dimensional axially symmetric WC is analyzed in the paper and the velocity of the cavity plasma removal during the development of the threedimensional axially symmetric WC is estimated. The availability of three directions of flows removing the elementary plasma volumes from the cavity relative to the observer's gaze is demonstrated for the considered type of WC. One direction of the flow is realized when the elementary volume of the plasma moves away from the observer and the other - toward him. The third direction of the flow is transverse to the observer's gaze direction. At that, the velocity of the removal of elementary plasma volumes is zero. It is concluded that the existence of such motions of elementary plasma volumes can leave a definite imprint on the parameters of the synthesis products in them. By the example of antineutrinos generated as a result of the development of WC in the plasma core of the Sun and located in reference frames moving in opposite directions from the observer, it is demonstrated that the path difference between them is of the order of the oscillation length in the solar core. 


\section{REFERENCES}

1. Fizicheskaya e 'ncziklopediya: [t. 5] / Gl. red. A. M. Prokhorov, redkol.: D.M. Alekseev i dr. M. T. 5: Stroboskopicheskie pribory' - Yarkost'. Bol'shaya ros. e'nczikl. 1998, 760 s. (in Russian).

2. http://nuclphys.sinp.msu.ru/astro/astro12.htm

3. G.V. Klapdor-Klajngrotkhaus, K. Czyuber. Astrofizika e lementarny kh chasticz. M.: «Uspekhi fizicheskikh nauk», 2000, 496 s. (in Russian).

4. D.V. Naumov. Vvedenie $\mathrm{v}$ fiziku nejtrino // Pis' $m a v$

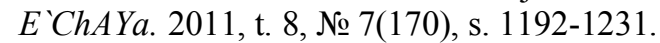

5. Alexander Kosovichev and Jean-Pierre Rozelot. Cyclic Changes of the Sun's Seismic Radius // The Astrophysical Journal. 2018, v. 861, № 2, p. 1-5.

6. E. Fossat, P. Boumier, T. Corbard, et al. Asymptotic g modes: Evidence for a rapid rotation of the solar core // Astronomy and Astrophysics. 2017, v. 604, A40.

7. E. Zakharov. Collapse and Self-focusing of Langmuir Waves // Handbook of Plasma Physics / Eds. M.N. Rosenbluth and R.Z. Sagdeev, v. 2 / Eds. A.A. Galeev and R.N. Sudan. 1984, p. 81-121.

8. V.E. Zakharov. Collapse of Langmuir waves // JETP. 1972, v. 35, p. 908-914.

9. A. Hasegawa. Solitons in Optical Communications // Clarendon Press, Oxford, NY, 1995.

10. B.A. Malomed. Variational methods in nonlinear fiber optics and related fields // Progress in Optics. 2002, v. 43, p. 69-191.

11. R.E. Kates, D.J. Kaup // Astronomy and Astrophysics. 1988, v. 206, № 1, p. 9-17.
12. T.B. Benjamin and J.E. Feir. The disintegration of wavetrains in deep water, Part $1 / / \mathrm{J}$. Fluid Mech. 1967, v. 27, p. 417-430.

13. M. Onorato, A.R. Osborne, M. Serio, and S. Bertone. Freak waves in random oceanic sea states // Phys. Rev. Lett. 2001, v. 86, p. 5831-5834.

14. S.F. Skoromnaya, V.I. Tkachenko. Self-Similar Solutions of Multi-Dimensional Nonlinear Schrödinger Equations // Problems of Atomic Science and Technology. Series "Plasma Electronics and New Methods of Acceleration”. 2008, № 4, p. 237-241.

15. J. Ablowitz and H. Segur. Solitons and the Inverse Scattering Transform, SIAM (Philadelphia, 1981). M.J. Ablowitz and P.A. Clarkson. Solitons, Nonlinear Evolution Equations and Inverse Scattering // Cambridge University Press (Cambridge, 1991). MR0642018 (84a:35251), MR1149378 (93g:35108)

16. M.J. Ablowitz, B. Prinari and A.D. Trubatch. Discrete and Continuous Nonlinear SchrËodinger Systems // Cambridge University Press, Cambridge, 2004. MR2040621(2005c:37117).

17. C. Sulem, P.-L. Sulem. The Nonlinear Schrödinger Equation. Self-Focusing and Wave Collapse. Springer // Applied Mathematical Sciences. 1999, v. $139,322 \mathrm{p}$.

18. V.E. Zakharov, E.A. Kuzneczov. Kvaziklassicheskaya teoriya trekhmernogo volnovogo kollapsa // ZhTE'F. 1986, t. 91, v. 4(10), p. 1310-1324 (in Russian).

19. E.A. Kuzneczov. Integral'ny'e kriterii volnovy'kh kollapsov. Izv. Vuzov // Radiofizika. 2003, t. XLVI, № 5, 6, p. 342-359 (in Russian).

Article received 10.03.2020

\section{НЕСТАЦИОНАРНАЯ МОДЕЛЬ ЯДРА СОЛНЦА}

\section{С.Ф. Скоромная, В.И. Ткаченко}

Рассмотрены основные параметры стандартной модели Солнца, согласно которой Солнце рассматривается как сферически-симметричная и квазистатическая звезда, а внутри нее в основном протекают термоядерные реакции рр-цикла, и происходит равномерное выделение энергии со скоростью $E=2 \cdot 10^{-4}$ Дж/(кг с). Исходя из наблюдательных данных, сделан вывод о том, что Солнце не является звездой с равномерно текущими процессами, ему присущи колебательные процессы и вспышки. Предложено рассматривать нестационарную модель Солнца, в которой необходимо учитывать существование электромагнитных волн в плазме ядра Солнца и, как следствие, существование волновых коллапсов (ВК). Рассмотрен трехмерный аксиально-симметричный ВК, и дана оценка скорости выноса плазмы ядра Солнца при развитии трехмерного аксиально-симметричного ВК. Для рассмотренного ВК показано существование трех направлений потоков элементарных объемов плазмы относительно наблюдателя: одно направление обусловлено движением элементарного объема плазмы от наблюдателя, другое - к нему. Третье направление движения элементарных объемов плазмы осуществляется перпендикулярно направлению наблюдения, и скорость их движения относительно наблюдателя равна нулю. Сделан вывод о том, что существование таких движений элементарных объемов плазмы при развитии ВК может накладывать определенный отпечаток на параметры продуктов синтеза в них.

\section{НЕСТАЦІОНАРНА МОДЕЛЬ ЯДРА СОНЦЯ}

\section{С.Ф. Скоромна, В.І. Ткаченко}

Розглянуто основні параметри стандартної моделі Сонця, згідно з якою Сонце розглядається як сферичносиметрична і квазістатична зірка, а всередині неї протікають переважно термоядерні реакції рр-циклу, і відбувається рівномірне виділення енергії зі швидкістю $E=2 \cdot 10^{-4}$ Дж/(кг сс). Виходячи із спостережних даних, зроблено висновок про те, що Сонце не $\epsilon$ зіркою з рівномірно поточними процесами, йому притаманні коливальні процеси і спалахи. Запропоновано розглядати нестаціонарну модель Сонця, в якій необхідно враховувати існування електромагнітних хвиль в плазмі ядра Сонця i, як наслідок, існування хвильових колапсів (ХК). Розглянуто тривимірний аксіально-симетричний $\mathrm{XК,} \mathrm{i} \mathrm{дана} \mathrm{оцінка} \mathrm{швидкості} \mathrm{виносу} \mathrm{плазми} \mathrm{ядра} \mathrm{Сонця} \mathrm{при} \mathrm{розвитку} \mathrm{тривимірного} \mathrm{аксіально-симетричного} \mathrm{ХК.} \mathrm{Для}$ розглянутого ХК показано існування трьох напрямків потоків елементарних обсягів плазми відносно спостерігача: один напрямок обумовлено рухом елементарного обсягу плазми від спостерігача, інший - до нього. Третій напрям руху елементарних обсягів плазми здійснюється перпендикулярно напрямку спостереження, i швидкість їх рухів відносно спостерігача дорівнює нулю. Зроблено висновок про те, що існування таких рухів елементарних обсягів плазми при розвитку ХК може накладати певний відбиток на параметри продуктів синтезу в них. 